\title{
Association between polymorphisms in XRCC1 gene and clinical outcomes of patients with lung cancer: a meta-analysis
}

Zhigang Cui ${ }^{1 \dagger}$, Zhihua Yin ${ }^{2,3 \dagger}$, Xuelian $\mathrm{Li}^{2,3}$, Wei Wu ${ }^{2,3}$, Peng Guan ${ }^{2,3}$ and Baosen Zhou ${ }^{2,3,4^{*}}$

\begin{abstract}
Background: X-ray repair cross-complementing group 1 (XRCC1) protein plays an important role in the repair of DNA damage and adducts. Single nucleotide polymorphisms (SNPS) of XRCC1 are suspected to have some relationship with response to chemotherapy and overall survival of lung cancer. This meta-analysis aimed to summarize published data on the association between the commonest SNPs of XRCC1 (Arg194Trp, C > T, rs1799782 and Arg399GIn, G > A, rs25487) and clinical outcome of lung cancer patients.

Methods: We retrieved the relevant articles from PubMed, EMBASE and the China National Knowledge Infrastructure (CNKI) databases. Studies were selected using specific inclusion and exclusion criteria. Primary outcomes included objective response (i.e., complete response + partial response vs. progressive disease + stable disease) and overall survival (OS). Odds ratio (OR) or hazard ratio (HR) with 95\% confidence interval (Cl) were estimated. All analyses were performed using the Stata software.
\end{abstract}

Results: Twenty-two articles were included in the present analysis. XRCC1 Arg194Trp and Arg399GIn polymorphisms were significantly associated with response to treatment in lung cancer patients. Patients with $\mathrm{C} / \mathrm{T}$ genotype, T/T genotype and minor variant T allele at Arg194Trp were more likely to respond to platinum-based chemotherapy compared with those with $\mathrm{C} / \mathrm{C}$ genotype (C/T vs. C/C: OR, 2.54; 95\%Cl, 1.95-3.31; T/T vs. C/C: OR, 2.06; 95\%Cl, 1.39-3.06; C/T+T/T vs. C/C: OR, 2.42; 95\% Cl, 1.88-3.10). For XRCC1 Arg399Gln, G/A genotype, A/A genotype and minor variant $A$ allele were associated with objective response in all patients (G/A vs. G/G: OR, 0.67; 95\%Cl, 0.50-0.90; A/A vs. G/G: OR, 0.43; 95\%Cl, 0.25-0.73; A/A+G/A vs. G/G: OR, 0.63; 95\%Cl, 0.49-0.83). Both G/A and A/A genotypes of XRCC1 Arg399GIn could influence overall survival of lung cancer patients (G/A vs. G/G: HR, 1.23; $95 \% \mathrm{Cl}, 1.06-1.44 ; \mathrm{A} / \mathrm{A}$ vs. G/G: HR, 2.03; 95\%Cl, 1.20-3.45). Interaction analysis suggested that compared with the patients carrying C/T+T/T genotype at XRCC1 194 and G/G genotype at XRCC1 399, the patients carrying 194 C/C and $399 \mathrm{G} / \mathrm{A}+\mathrm{A} / \mathrm{A}$ or $194 \mathrm{C} / \mathrm{C}$ and $399 \mathrm{G} / \mathrm{G}$ genotype showed much worse objective response.

Conclusions: Genetic polymorphisms in XRCCI gene might be associated with overall survival and response to platinum-based chemotherapy in lung cancer patients.

\section{Background}

Lung cancer as a major public health problem represents the most common cancer, and more than a million people in the world die from the disease each year [1]. Despite the recent advances, the overall five-year survival rate of lung cancer is at only $15 \%$ in the United

\footnotetext{
* Correspondence: bszhou@mail.cmu.edu.cn

+ Contributed equally

${ }^{2}$ Department of Epidemiology, School of Public Health, China Medical

University, Shenyang 110001, PR China

Full list of author information is available at the end of the article
}

States and even lower in China [2]. Platinum is one of the most extensively used chemotherapeutic agents in lung cancer treatment, especially for the patients in advanced stages. However, the efficacy of platinumbased chemotherapy varied remarkably between different individuals, with a response rate from $26 \%$ to $60 \%$ in lung cancer patients [3]. Genetic factors are considered to influence the treatment effectiveness of lung cancer [4], thus affect the prognosis of patients. There are some molecular markers showing potential as therapeutic and prognostic indicators, but none could be used
C Biomed Central 
into clinical practice $[5,6]$. In these factors, DNA repair capacity (DRC) is an important one. The previous study has reported that effective host DRC may be associated with poorer survival in patients with non-small cell lung cancer (NSCLC) who are treated with chemotherapy [7]. It has been speculated that single nucleotide polymorphisms (SNPs) in DNA repair genes may change gene expression and activity, hence influence the effectiveness of cancer treatment and survival of patients [8]. X-ray repair cross-complementing group 1 (XRCC1) protein plays a central role in base excision repair (BER) pathway by interacting with other DNA repair proteins, giving the possibility that $X R C C 1$ has some relationship with the response to therapy and the overall survival of lung cancer.

The XRCC1 gene was identified by its function to restore the DNA repair capacity in the Chinese hamster ovary mutant cell line EM9 [9] and interact with poly (ADP-ribose) polymerase and DNA ligase III in recognizing and rejoining DNA strand breaks, as well as with DNA polymerase $\beta$ and apurinic/apyrimidinic endonuclease I [10-13]. The most extensively studied SNPs of XRCC1 gene are Arg399Gln (G > A, rs25487) and Arg194Trp ( $\mathrm{C}>\mathrm{T}$, rs1799782), which have been reported to be associated with an altered DNA repair activity $[14,15]$. These polymorphisms that lead to amino acid changes might alter the efficiency of DNA repair and have functional significance. The functional effect of these polymorphisms is not clear, even though there are studies suggesting that amino acid substitutions at the evolutionary conserved regions can affect the protein ability [16]. Lamerdin et al. found that XRCC1 gene codon 194 was at a conserved residue in humans [17], suggesting the functional significance of this site. Theoretically, these polymorphisms could affect the response to cancer therapy through the removal of DNA adducts, in hence influence the overall survival of patients.

Some studies have reported the relationship between polymorphisms in XRCC1 gene and clinical outcome or overall survival of lung cancer patients [18-39], however the results were inconsistent. So we performed a systemic review and meta-analysis to assess the evidence about effects of XRCC1 SNPs on the efficacy of chemotherapy and overall survival in lung cancer patients.

\section{Methods}

\section{Data sources}

This meta-analysis focused on studies dealing with prognostic implication of XRCC1 SNPs in patients with lung cancer. We conducted this systematic review using a peer-reviewed, published protocol according to the guidelines of the Cochrane Collaboration. We retrieved the relevant articles using the following terms "XRCC1 or X-ray repair cross complementing protein 1 " and "lung cancer or lung neoplasms" and "SNP or polymorphism" from PubMed, EMBASE and the China National Knowledge Infrastructure (CNKI) databases.

\section{Study selection and data extraction}

Flow chart of the study selection process was shown in Figure 1. Duplicate and obviously unrelated articles were eliminated by a single reviewer (Z.C.). Abstracts of the remaining articles were examined independently by three reviewers (Z.C., Z.Y., and X.L.) to determine whether the full-text article should be obtained. Articles published in English or Chinese language, peer-reviewed journals that assessed the relationship between germline polymorphic variants and major outcomes of interest were included. We selected related studies using following inclusion criteria:

(1) Studies should contain the information to estimate relative risks (i.e., Odds ratios [ORs], hazard ratios [HRs]) and 95\% confidence intervals (CIs) for prognostic effect of lung cancer.

(2). The cases in studies should be advanced, recurrent, or metastatic lung cancer patients treated by any of the platinum drugs.

(3) Cancer patients should be histologically or pathologically confirmed.

(4) SNPs in XRCC1 gene should be genotyped.

(5) The studies with cell line would be excluded.

According to these criteria, a total of 37 articles were selected. Five studies were excluded because data that overlapped from the same study group were published. Three studies were excluded because critical missing information was not obtained. As the number of relevant studies was not enough, two studies with SNPs rs25489, rs2854510 and rs1001581 in XRCC1 gene, two studies with XRCC1 T-77C, and two studies with toxicity were also excluded. One study only about XRCC1 protein was also excluded. Finally we summarized the results of 22 articles for our systematic review (Table 1).

The following information were extracted and coded by using standard form: year of publication, country/ region of study, ethnicity, case number, cancer stage of samples, outcomes and SNPs included in each study.

\section{Statistical methods}

We abstracted ORs, HRs and 95\%CIs from all studies. If such data were missing from some studies, we calculated the ORs and 95\%CIs for objective response vs. no response after platinum-based chemotherapy [complete response $(C R)+$ partial response $(P R)$ vs. progressive disease (PD) + stable disease (SD)] using the WHO criteria or the Response Evaluation Criteria in Solid Tumors (RECST). We then investigated the betweenstudy heterogeneity by the Cochran's Q test (a 


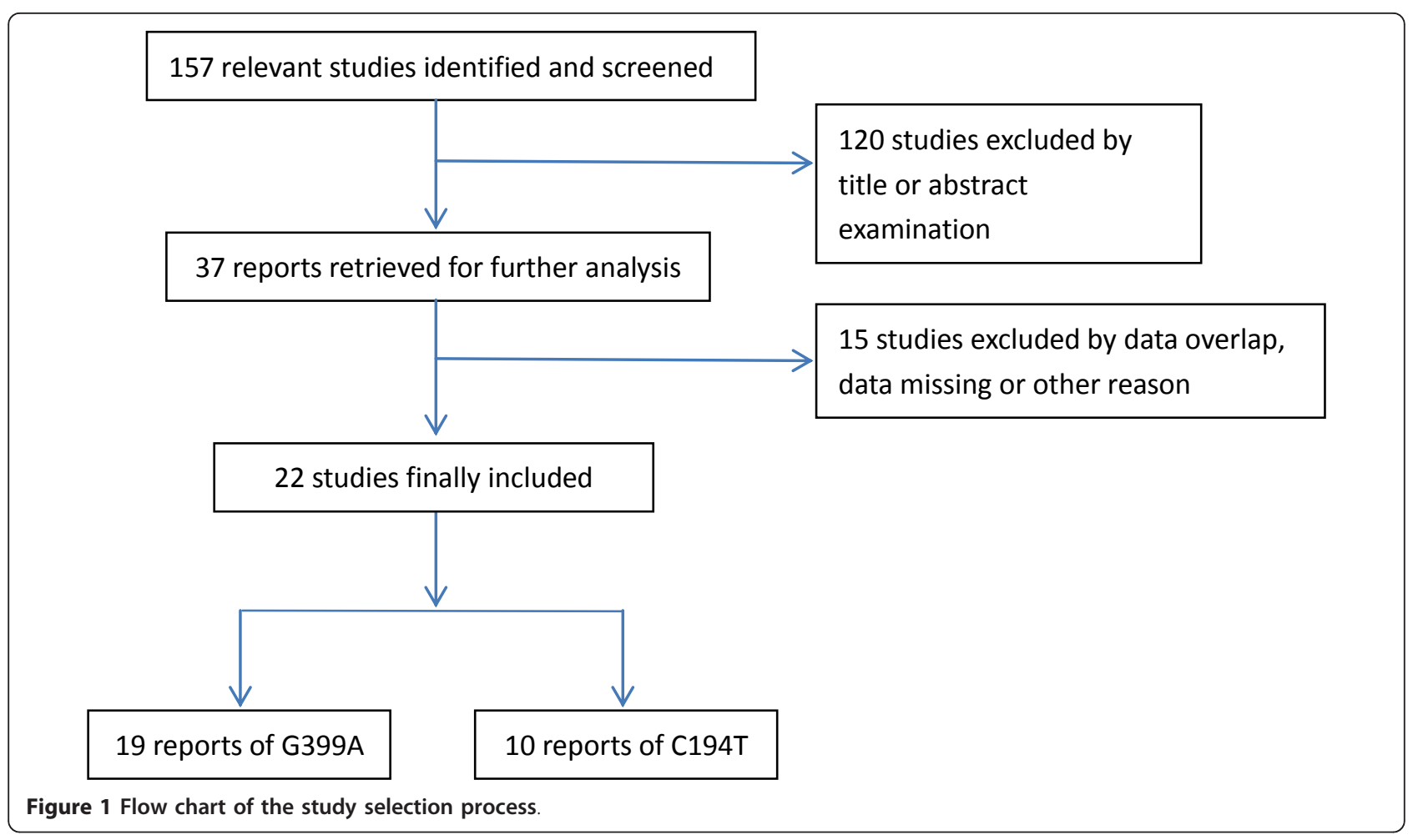

Table 1 Studies on prognosis and XRCC1 Arg194Trp and Arg399GIn polymorphisms included in the meta-analysis

\begin{tabular}{|c|c|c|c|c|c|c|c|}
\hline Study & Year & Country & Ethnicity & Case No. & Stage & Outcome & SNPs \\
\hline Gao et al. [24] & 2006 & China & Asian & 57 & II-IV & TR & XRCC1 Arg194Trp and Arg399GIr \\
\hline Ding et al. [25] & 2010 & China & Asian & 54 & IIIB-IV & TR & XRCC1 Arg399Gln \\
\hline Yuan et al. [26] & 2006 & China & Asian & 200 & advanced & TR & XRCC1 Arg194Trp \\
\hline Shi et al. [27] & 2006 & China & Asian & 112 & II-IV & TR & XRCC1 Arg194Trp and Arg399GIr \\
\hline Qiu et al. [28] & 2009 & China & Asian & 107 & IIIA/B-IV & TR & XRCC1 T-77C and Arg194Trp \\
\hline Sun et al. [18] & 2009 & China & Asian & 87 & IV & TR & XRCC1 Arg194Trp and Arg399GIr \\
\hline Song et al. [19] & 2007 & China & Asian & 97 & IIIB-IV & TR & XRCC1 Arg194Trp and Arg399GIr \\
\hline Wang et al. [20] & 2004 & China & Asian & 105 & IIIB-IV & TR & XRCC1 Arg194Trp and Arg399GIr \\
\hline Hong et al. [21] & 2009 & China & Asian & 164 & III-IV & TR & XRCC1 Arg194Trp and Arg399GIr \\
\hline Jin et al. [22] & 2006 & China & Asian & 162 & IIIB-IV & TR & XRCC1 Arg194Trp \\
\hline Qian et al. [23] & 2010 & China & Asian & 107 & IIIA/B-IV & TR & XRCC1 Arg399GIn \\
\hline Cheng et al. [29] & 2011 & China & Asian & 120 & advanced & TR & XRCC1 Arg399Gln \\
\hline Giachino et al. [30] & 2007 & Italy & Caucasian & 248 & IIIA/B-IV & TR/OS & XRCC1 Arg399GIn \\
\hline Butkiewicz et al. [31] & 2010 & Poland & Caucasian & 162 & I, II or IIIA & OS & XRCC1 Arg399GIn \\
\hline de las Penas R. et al. [32] & 2006 & Spain & Caucasian & 135 & IIIB-IV & OS & XRCC1 Arg399GIn \\
\hline Yin et al. [33] & 2009 & China & Asian & 257 & I- IV & OS & XRCC1 Arg399GIn \\
\hline Sreeja et al. [34] & 2008 & India & Caucasian & 211 & I- IV & OS & XRCC1 Arg399GIn \\
\hline Gurubhagavatula et al. [35] & 2004 & USA & Caucasian & 103 & IIIA/B-IV & OS & XRCC1 Arg399Gln \\
\hline Kalikaki et al. [36] & 2009 & Greece & Caucasian & 119 & IIIA/B-IV & TR/OS & XRCC1 Arg399GIn \\
\hline Liu et al. [37] & 2008 & China & Asian & 53 & I- IV & OS/PFS & XRCC1 Arg399GIn \\
\hline Han et al. [38] & 2011 & Korea & Asian & 158 & IIIB-IV & OS/PFS & XRCC1 Arg399GIn \\
\hline Yao et al. [39] & 2009 & China & Asian & 108 & IIIA/B-IV & OS & XRCC1 Arg399GIn \\
\hline
\end{tabular}

TR: objective response

OS: overall survival

PFS: progression-free survival 
significance level of $\mathrm{P}<0.05)$ and quantified by $\mathrm{I}^{2}$. To obtain summary statistics for HRs of overall survival or ORs of chemotherapy response, we performed initial analyses with a fixed-effect model, and confirmatory analyses with a random-effect model if there was significant heterogeneity. The effect of publication bias was examined by inverted funnel plots and the Begg's test. All of P values were two-sided and all analyses were performed using the Stata software version 11.0 (Stata Corp, College station, TX).

\section{Results}

The data pool was composed of 22 studies. Sample sizes ranged from 53 to 257 (median 115.5), including 294 stage I/II and 2632 stage III/IV (total 2926) lung cancer patients (Table 1).

\section{XRCC1 Arg194Trp}

Since the study on the association between XRCC1 Arg194Trp polymorphism with PFS or OS was too few to be applied in the present meta-analysis, we only analyzed the association of XRCC1 Arg194Trp polymorphism and objective response in lung cancer patients.

Ten studies including 1145 patients were eligible for final analysis. The patients bearing the favorable XRCC1 194 genotypes $(\mathrm{C} / \mathrm{T}, \mathrm{T} / \mathrm{T})$ were more likely to respond to platinum-based chemotherapy compared with those with the unfavorable genotype $(\mathrm{C} / \mathrm{C})(\mathrm{C} / \mathrm{T}$ vs. $\mathrm{C} / \mathrm{C}$ : $\mathrm{OR}$, 2.54; 95\% CI, 1.95-3.31; $\mathrm{P}=0.590$ for heterogeneity, $\mathrm{I}^{2}=$ $0.0 \%$; $/ \mathrm{T}$ vs. C/C: OR, 2.06; $95 \% \mathrm{CI}, 1.39-3.06$; $\mathrm{P}=$ 0.888 for heterogeneity, $\mathrm{I}^{2}=0.0 \%$ ) (Figure 2). In the dominant model, the minor variant $\mathrm{T}$ allele also significantly influenced the objective response in all patients (C/T+T/T vs. $\mathrm{C} / \mathrm{C}$ : OR, $2.42 ; 95 \% \mathrm{CI}, 1.88-3.10 ; \mathrm{P}=$ 0.830 for heterogeneity, $\left.\mathrm{I}^{2}=0.0 \%\right)$. No publication bias was detected by either the inverted funnel plot or Begg's test (data not shown).

\section{XRCC1 Arg399GIn}

\section{Objective response}

There were ten studies, altogether 1021 patients, qualified for final analysis. As shown in Figure 3, the XRCC1 Arg399Gln polymorphism was significantly associated with response to platinum-based chemotherapy. In the dominant model, the G/A and A/A genotypes of XRCC1 399 polymorphism were statistically significantly associated with unfavorable objective response in patients treated with platinum-based chemotherapy (G/ A vs. G/G: OR, 0.67; 95\% CI, 0.50-0.90; $P=0.159$ for heterogeneity, $\mathrm{I}^{2}=32.4 \%$; A/A vs. G/G: OR, 0.43; $95 \%$ CI, 0.25-0.73; $\mathrm{P}=0.965$ for heterogeneity, $\left.\mathrm{I}^{2}=0.0 \%\right)$. The patients with either one or two minor variant $\mathrm{A}$ allele showed poorer objective response in all patients
(G/A+A/A vs. G/G: OR, 0.63; 95\% CI, 0.49-0.83; P = 0.206 for heterogeneity, $\mathrm{I}^{2}=25.8 \%$ ) (Figure 3 ). No publication bias was indicated according to the results of the inverted funnel plot and Begg's test (data not shown).

\section{Overall survival}

G/A genotype and A/A genotype A total of eight studies (1288 patients) were included in this part of analysis. Variant genotypes of XRCC1 399 polymorphism were associated with higher risks of death for lung cancer patients (Figure 4). With the G/G genotype at XRCC1 Arg399Gln being the reference, the HR for G/A genotype was 1.23 compared to 2.03 in the $\mathrm{A} / \mathrm{A}$ genotype (G/A vs. G/G: HR, 1.23; 95\% CI, 1.06-1.44; P = 0.557 for heterogeneity, $\mathrm{I}^{2}=0.0 \%$; A/A vs. G/G: HR, 2.03 ; $95 \% \mathrm{CI}, 1.20-3.45 ; \mathrm{P}=0.000$ for heterogeneity, $\mathrm{I}^{2}=$ $85.9 \%)$. No publication bias was found through either the funnel plot or Begg's test (data not shown).

Minor variant A allele Three studies including 428 patients were eligible for analyzing the relationship between alleles of XRCC1 399 polymorphism and overall survival. In the dominant model, there was no evidence for an influence of XRCC1 399 A allele on overall survival of lung cancer patients (G/A and A/A vs. G/G: HR, 1.18; $95 \% \mathrm{CI}, 0.93-1.50 ; \mathrm{P}=0.329$ for heterogeneity, $\mathrm{I}^{2}=$ 10.2\%) (Figure 4C).

\section{Interaction of XRCC1 Arg194Trp and Arg399Gln polymorphisms on the objective response}

Four studies including 371 patients were used to analyze the relationship of the combinations between XRCC1 Arg194Trp and Arg399Gln genotypes with the objective response in lung cancer patients. According to above results in the present study and the results in available studies analyzing the combination of SNPs, we defined combination of XRCC1 $194 \mathrm{C} / \mathrm{T}+\mathrm{T} / \mathrm{T}$ genotype and XRCC1 399 G/G genotype as reference group. Combination of XRCC1 194 C/T+T/T genotype and XRCC1 399 $\mathrm{G} / \mathrm{A}+\mathrm{A} / \mathrm{A}$ genotype were not significantly associated with objective response (OR, 0.72; 95\% CI, 0.39-1.33; P $=0.383$ for heterogeneity, $\left.\mathrm{I}^{2}=1.8 \%\right)$. Combination of XRCC1 194 C/C genotype and XRCC1 399 G/G genotype were significantly associated with objective response (OR, 0.27; 95\% CI, 0.14-0.53; $\mathrm{P}=0.427$ for heterogeneity, $\left.\mathrm{I}^{2}=0.0 \%\right)$. Combination of XRCC1 $194 \mathrm{C} / \mathrm{C}$ genotype and XRCC1 $399 \mathrm{G} / \mathrm{A}+\mathrm{A} / \mathrm{A}$ genotype were significantly associated with objective response in all patients (OR, 0.37; 95\% CI, 0.22-0.65; $\mathrm{P}=0.449$ for heterogeneity, $\mathrm{I}^{2}=0.0 \%$ ) (Figure 5 ).

Table 2 summarized the association between XRCC1 Arg194Trp and Arg399Gln polymorphisms with response and overall survival in fixed-effect models and random-effect models, respectively. $P$ values for the between-study heterogeneity were also listed in Table 2 . 


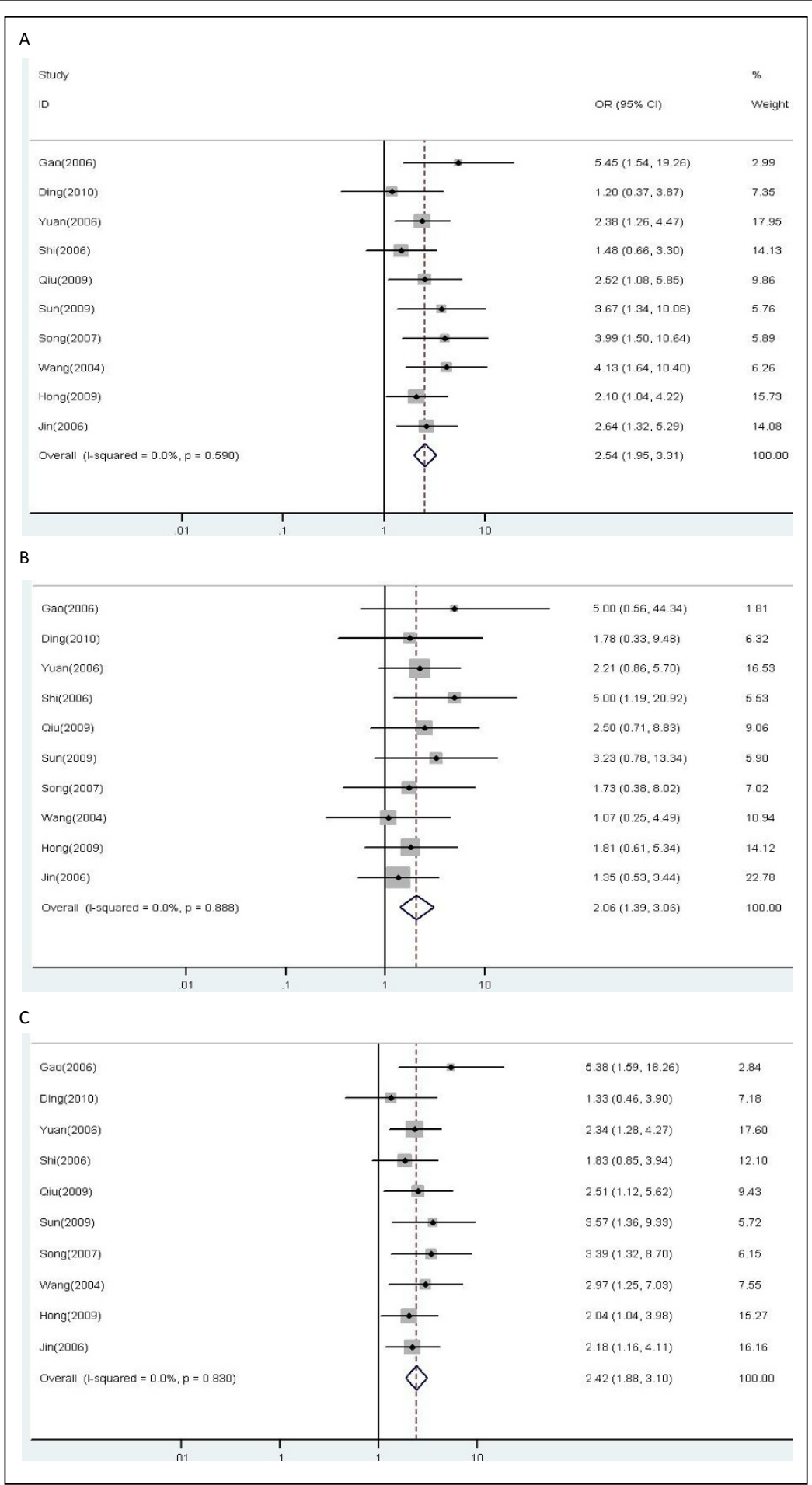

Figure 2 Forest plot of objective response in lung cancer patients treated with chemotherapy by XRCC1 Arg194Trp polymorphism: (A) $C / T$ vs. $C / C ;(B) T / T$ vs. $C / C$; (C) $C / T+T / T$ vs. $C / C$.

\section{Discussion}

There have been previous studies investigating possible associations between XRCC1 SNPs and chemotherapy outcomes or overall survival of lung cancer [18-39].
However these original results are inconsistent and until now the lack of systematic review evaluation failed to give further insights on this issue. We showed, by an extensive quantitative and systematic review of 


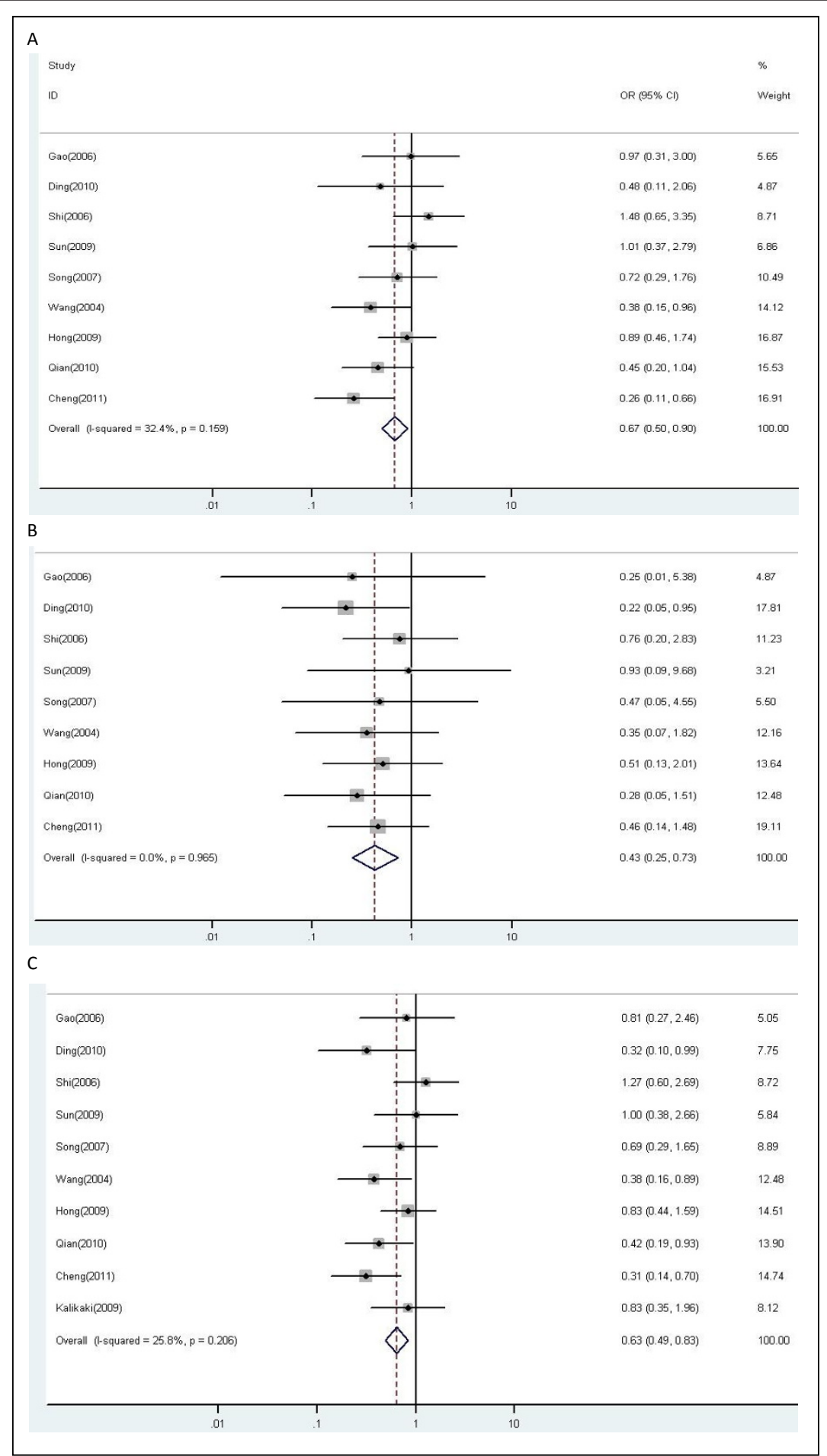

Figure 3 Forest plot of objective response in lung cancer patients treated with chemotherapy by XRCC1 Arg399Gln polymorphism: (A) G/A vs.G/G; (B) A/A vs. G/G; (C) G/A+A/A vs.G/G.

published reports, that XRCC1 194 C/T and XRCC1 399 G/A SNPs were associated with objective response and XRCC1 399 G/A genotype and A/A genotype could influence overall survival of lung cancer patients.
Furthermore, interaction analysis suggested that compared with the patients carrying $\mathrm{C} / \mathrm{T}+\mathrm{T} / \mathrm{T}$ genotype at XRCC1 194 and G/G genotype at XRCC1 399, the patients carrying $194 \mathrm{C} / \mathrm{C}$ and $399 \mathrm{G} / \mathrm{A}+\mathrm{A} / \mathrm{A}$ or $194 \mathrm{C} /$ 


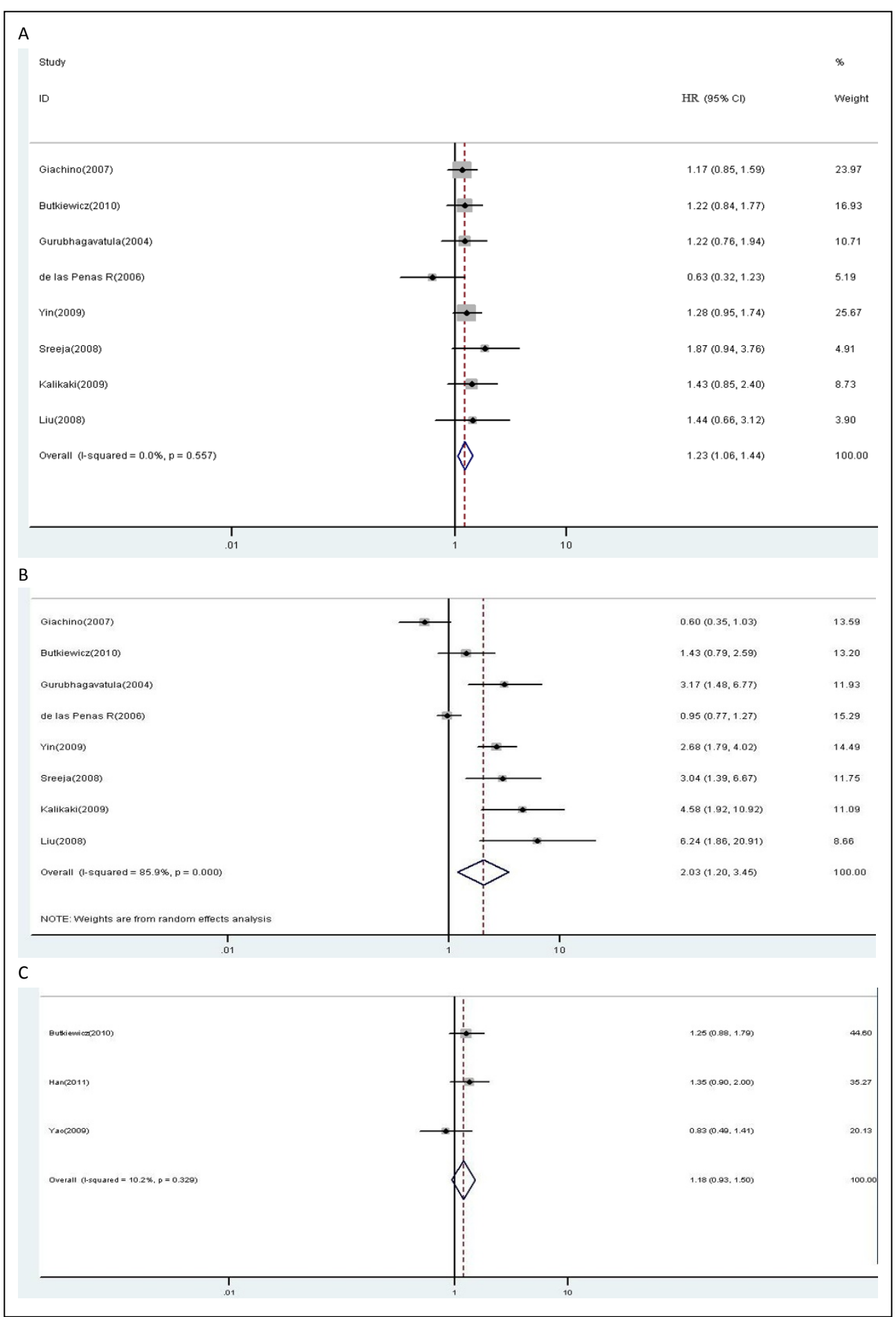

Figure 4 Forest plot of overall survival in lung cancer patients treated with chemotherapy by XRCC1 Arg399Gln polymorphism: (A) G/ A vs.G/G; (B) A/A vs. G/G; (C) G/A+A/A vs.G/G.

C and 399 G/G genotype showed much worse objective response.

Platinum agents are activated intracellularly to form reactive platinum complexes that bind to DNA, thereby inducing intrastrand and interstrand DNA cross-links, as well as DNA-protein cross-links. These platinuminduced DNA and protein effects result in apoptosis and cell growth inhibition. There are several signal 


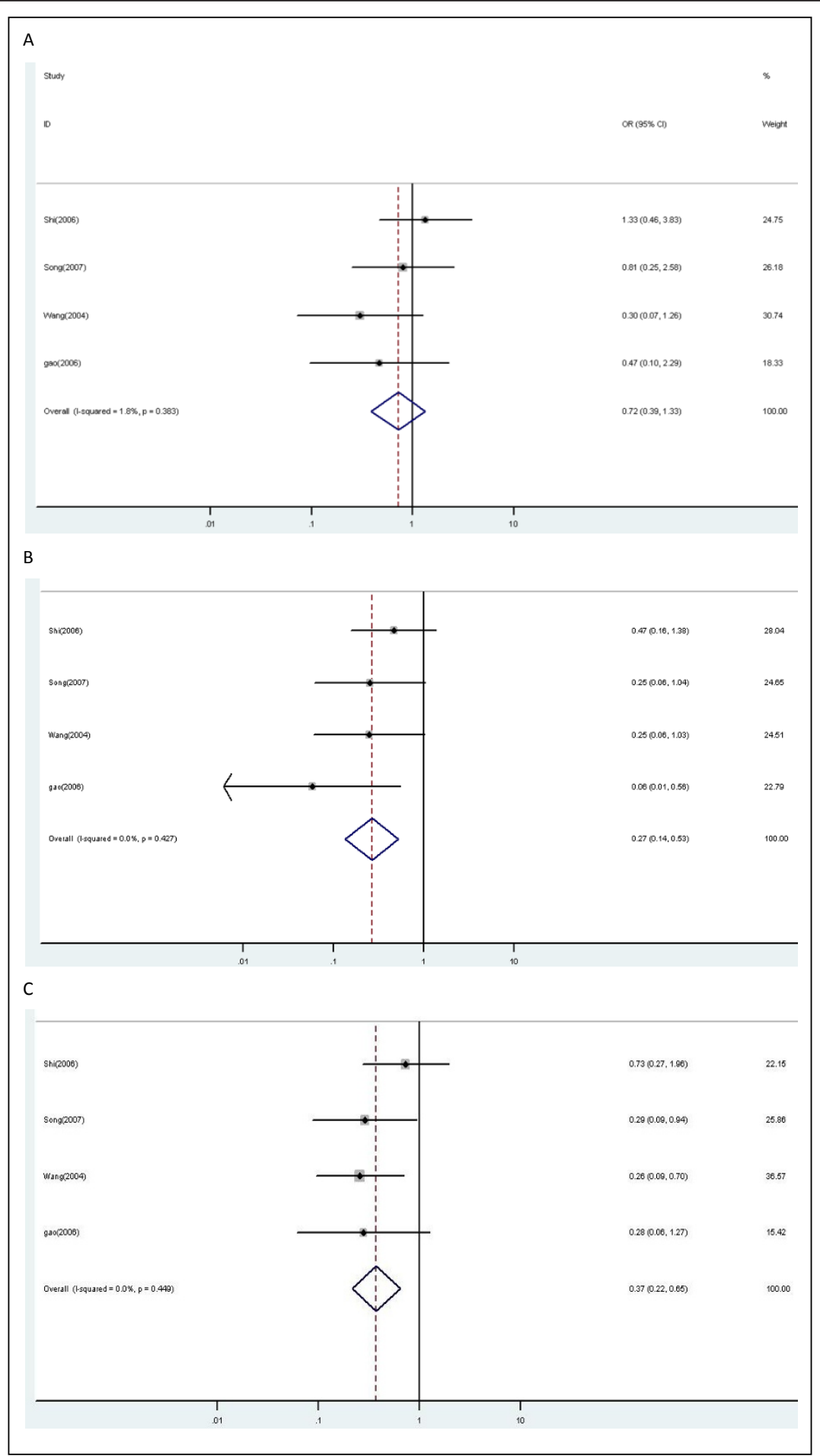

Figure 5 Forest plot of objective response in lung cancer patients treated with chemotherapy by combinations of XRCC1 Arg194Trp and XRCC1 Arg399Gln polymorphisms: (A) combination of $194 \mathrm{C} / \mathrm{T}+\mathrm{T} / \mathrm{T}$ and $399 \mathrm{G} / \mathrm{A}+\mathrm{A} / \mathrm{A}$ vs. combination of $194 \mathrm{C} / \mathrm{T}+\mathrm{T} / \mathrm{T}$ and $399 \mathrm{G} / \mathrm{G} ;(\mathrm{B})$ combination of $194 \mathrm{C} / \mathrm{C}$ and $399 \mathrm{G} / \mathrm{G}$ vs. combination of $194 \mathrm{C} / \mathrm{T}+\mathrm{T} / \mathrm{T}$ and $399 \mathrm{G} / \mathrm{G}$; (C) combination of $194 \mathrm{C} / \mathrm{C}$ and $399 \mathrm{G} / \mathrm{A}+\mathrm{A} / \mathrm{A}$ vs. combination of $194 \mathrm{C} / \mathrm{T}+\mathrm{T} / \mathrm{T}$ and $399 \mathrm{G} / \mathrm{G}$. 
Table 2 Association between XRCC1 Arg194Trp and Arg399GIn polymorphisms with objective response and overall survival

\begin{tabular}{|c|c|c|c|c|c|c|c|c|}
\hline \multirow{2}{*}{$\begin{array}{l}\text { XRCC1 } \\
\text { Arg194Trp }\end{array}$} & \multicolumn{4}{|c|}{ Objective response } & \multicolumn{4}{|c|}{ Overall survival } \\
\hline & Study & Fixed effect & Random effect & Phet* & Study & Fixed effect & Random effect & Phet* \\
\hline $\mathrm{C} / \mathrm{T}$ vs. $\mathrm{C} / \mathrm{C}$ & 10 & $2.54[1.95,3.31]$ & $2.54[1.95,3.32]$ & 0.590 & & & & \\
\hline T/T vs. C/C & 10 & $2.06[1.39,3.06]$ & $2.06[1.38,3.08]$ & 0.888 & & & & \\
\hline $\mathrm{T} / \mathrm{T}+\mathrm{C} / \mathrm{T}$ vs. $\mathrm{C} / \mathrm{C}$ & 10 & $2.42[1.88,3.10]$ & $2.41[1.87,3.10]$ & 0.830 & & & & \\
\hline $\mathrm{XRCC1}$ & \multicolumn{4}{|c|}{ Objective response } & \multicolumn{4}{|c|}{ Overall survival } \\
\hline Arg399Gln & Study & Fixed effect & Random effect & Phet* & Study & Fixed effect & Random effect & Phet* $^{*}$ \\
\hline G/A vs. G/G & 9 & $0.67[0.50,0.90]$ & $0.67[0.46,0.97]$ & 0.159 & 8 & $1.23[1.06,1.44]$ & $1.23[1.06,1.44]$ & 0.557 \\
\hline A/A vs. G/G & 9 & $0.43[0.25,0.73]$ & $0.43[0.25,0.84]$ & 0.965 & 8 & $1.41[1.19,1.67]$ & $2.03[1.20,3.45]$ & 0.000 \\
\hline $\mathrm{A} / \mathrm{A}+\mathrm{G} / \mathrm{A}$ vs. $\mathrm{G} / \mathrm{G}$ & 10 & $0.63[0.49,0.83]$ & $0.63[0.46,0.86]$ & 0.206 & 3 & $1.18[0.93,1.50]$ & $1.18[0.92,1.51]$ & 0.329 \\
\hline \multirow[t]{2}{*}{ Interaction } & \multicolumn{4}{|c|}{ Objective response } & \multicolumn{4}{|c|}{ Overall survival } \\
\hline & Study & Fixed effect & Random effect & Phet $^{*}$ & Study & Fixed effect & Random effect & Phet* $^{*}$ \\
\hline c2 vs. C1 & 4 & $0.72[0.39,1.33]$ & $0.73[0.39,1.38]$ & 0.383 & & & & \\
\hline C3 vs. C1 & 4 & $0.27[0.14,0.53]$ & $0.28[0.14,0.57]$ & 0.427 & & & & \\
\hline C4 vs. C1 & 4 & $0.37[0.22,0.65]$ & $0.38[0.21,0.67]$ & 0.449 & & & & \\
\hline
\end{tabular}

Combinations of XRCC1 Arg194Trp and XRCC1 Arg399GIn polymorphisms: c1, combination of $194 \mathrm{C} / \mathrm{T}+\mathrm{T} / \mathrm{T}$ and $399 \mathrm{G} / \mathrm{G} ; \mathrm{c} 2$, combination of $194 \mathrm{C} / \mathrm{T}+\mathrm{T} / \mathrm{T}$ and $399 \mathrm{G} / \mathrm{A}+\mathrm{A} / \mathrm{A}$; c3: combination of $194 \mathrm{C} / \mathrm{C}$ and $399 \mathrm{G} / \mathrm{G} ; \mathrm{c} 4$, combination of $194 \mathrm{C} / \mathrm{C}$ and $399 \mathrm{G} / \mathrm{A}+\mathrm{A} / \mathrm{A}$.

*Phet: $\mathrm{P}$ values for the between-study heterogeneity.

transduction pathways involved in this process to exert antitumor effects, among which DNA damage recognition and repair are important. Cancer cells may be able to resist against the platinum-based chemotherapy when its DNA repair ability is enhanced to remove those DNA adducts caused by platinum agents. There is evidence that lung cancer patients with a lower DNA repair capacity had an increased overall survival after the first-line platinum-based chemotherapy [7].

Genetic polymorphisms can contribute directly to the variety in phenotypic drug sensitivity by modifying functions of the related genes. SNPs as either prognostic or predictive biomarkers have many advantages, especially in the advanced cancer setting. Firstly, it is relatively easy to obtain the human specimen for detecting SNP. Secondly, the method to detect SNP is precise and practical. Finally, some biomarkers are detected by specialized and mostly body-harmed methods; otherwise SNP detecting could avoid these problems.

The XRCC1 protein is considered to play an important role in DNA damage repair. XRCC1 Arg194Trp and Arg399Gln polymorphisms were the commonest one among more than 60 validated SNPs in XRCC1 gene and showed no major variations by ethnicity [40]. XRCC1 SNPs have been reported to be associated with an altered DNA repair activity $[14,15]$. Previous reports have also suggested that XRCC1 polymorphisms might be risk factors for the development of lung cancer [41-46] and promising predictive or prognostic makers for lung cancer patients [33-35,47]. Therefore, functional SNPs in XRCC1 gene may relate with platinum sensitivity and have prognostic values among lung cancer patients. With a pooled dataset of 2926 patients, we performed a comprehensive and systematic evaluation of clinical outcomes by objective response and overall survival. We are delighted to find the statistically significant association between XRCC1 SNPs with objective response and overall survival of lung cancer, which were not significant in previous original reports.

Meanwhile, the interaction between these two SNPs of $X R C C 1$ gene in the objective response was analyzed for the first time. It is important to analyze multiple SNPs and their interaction to find more reliable prognostic or predictive biomarkers, because it is hard to predict complex clinical outcomes of lung cancer patients by using only one SNP. Although there were only four original studies included in the present interaction analysis, the results are valuable. The results of interaction analysis showed that the patients carrying $194 \mathrm{C} / \mathrm{C}$ and $399 \mathrm{G} / \mathrm{A}$ $+\mathrm{A} / \mathrm{A}$ or $194 \mathrm{C} / \mathrm{C}$ and $399 \mathrm{G} / \mathrm{G}$ genotype showed worse objective response, suggesting C allele at XRCC1 194 may be more significantly associated with poorer objective response than A allele at XRCC1 399. The interaction between these two SNPs in objective response of lung cancer patients was not found. The reason may be the interaction between these two SNPs does not exist at all, or false positive report probability (FPRP) is too higher due to the small sample size. So future studies with large sample size on analyzing multiple genes may be necessary to explain the SNPs interaction.

There are three important questions should be addressed in interpreting the results of meta-analysis: (1) were all relevant studies included in the analysis? This is an important question but difficult to assess. We 
made every effort to search and collect studies that were sufficient to estimate impact of XRCC1 SNPs on clinical outcomes and survival of lung cancer as of June 2011; (2) was there heterogeneity in the study? The differences in study population including age, gender, smoking status, cancer histopathology type and cancer stage, in chemotherapy schedule of patients, and in measurement of confounding factors and others may result in study heterogeneity. In the present study, the between-study heterogeneity was analyzed by the Cochran's $\mathrm{Q}$ test $(\mathrm{P}<$ $0.05)$ and quantified by $\mathrm{I}^{2}$. Indeed, heterogeneous effects were observed in one subset in the present study. However, we could not separate studies further to obtain homogeneous groups because there was no information on confounding factors. So we performed initial analyses with a fixed-effect model and confirmatory analyses with random-effect model, if there was significant heterogeneity. At last we found the results were similar between fixed-effect model and random-effect model. On the other hand, when the studies, which are possible source of heterogeneity, were excluded from the analyses, there were similar results observed, which also showed that the heterogeneity did not appear to impact significantly on the results of our analyses; (3) publication bias is an important problem in meta-analysis and occurs if scientific studies with negative or null results fail to get published; this can happen due to bias in submitting, reviewing, accepting, publishing or aggregating scientific literature that fails to show positive results on a particular topic; and it could make scientific literature unrepresentative of the actual research studies [48]. In our results, no evidence of publication bias was found using standard tests such as inverted funnel and the Begg's test. However, we should know that these methodologies did not completely exclude biases, because there might have been rejection or even non-submission of negative results.

Despite our efforts in performing a comprehensive analysis, limitations of our meta-analysis need to be stated. First, most of the included studies differed in their study designs, such as subject selection, chemotherapeutic protocol et al. The patients in some studies also had surgery or other treatment such as radiotherapy in addition to the chemotherapy. All these confounding factors may influence the homogeneity between studies. Stratified analyses by possible confounding factors such as smoking history, cancer histology, and treatment method, might be able to reduce the heterogeneity as stated above. However, few of these studies reported SNP genotype distribution by subgroups so such analyses were impossible to implement. Second, our analyses mostly used unadjusted estimates, because not all published studies stated adjusted estimates, or when they stated, the estimates in different studies were adjusted by different possible confounding factors. However, when the available adjusted estimates were used in our analyses, the conclusions have not been significantly changed (data not shown). Third, we did not analyze the association between XRCC1 SNPs and progressionfree survival because there are only two studies involving progression-free survival. Fourth, the relationship between XRCC1 SNPs and platinum-based chemotherapy toxicities was not able to be analyzed in the present study, because few studies provided the related results.

In conclusion, our meta-analysis suggested that XRCC1 Arg194Trp and Arg399Gln polymorphisms may be associated with overall survival and response to platinum-based chemotherapy in lung cancer patients. Lung cancer patients with XRCC1 194 T allele or XRCC1 399 $G$ allele may benefit from platinum-based chemotherapy. However, to address these issues, future prospective studies with large sample size and even randomized clinical trials may be necessary. Besides, efforts on analyzing multiple genes to find more reliable prognostic or predictive biomarkers and even on studying gene-environment interaction should be made, because it is hard to predict complex clinical outcomes of lung cancer patients by using only single gene.

\section{Conclusions}

Genetic polymorphisms in XRCC1 gene might be associated with overall survival and response to platinumbased chemotherapy in lung cancer patients.

\section{Acknowledgements}

The authors are most grateful to all the participants in the present study. This study was supported by grant no.81102194 from National Natural Science Foundation of China, grant no.LS2010168 from Liaoning Provincial Department of Education, and grant no.00726 from China Medical Board.

\section{Author details}

${ }^{1}$ China Medical University, Shenyang 110001, PR China. ${ }^{2}$ Department of Epidemiology, School of Public Health, China Medical University, Shenyang 110001, PR China. ${ }^{3}$ Key Laboratory of Cancer Etiology and Intervention, University of Liaoning Province, Shenyang 110001, PR China. ${ }^{4}$ Department of Epidemiology, Key Laboratory of Cancer Etiology and Intervention, China Medical University, University of Liaoning Province, No. 92, North Second Road, Heping District, Shenyang 110001, People's Republic of China.

\section{Authors' contributions}

ZC participated in extracting the data, performing the statistical analysis and drafting the manuscript. ZY participated in selecting study, extracting data and drafting the manuscript. XL and WW collected and extracted the data. PG has been involved in revising the manuscript critically for important intellectual content. BZ conceived of the study and participated in drafting the manuscript. All authors read and approved the final manuscript.

\section{Competing interests}

The authors declare that they have no competing interests.

Received: 19 August 2011 Accepted: 17 February 2012 Published: 17 February 2012 


\section{References}

1. Guilbert JJ: The world health report 2002-reducing risks, promoting healthy life. Educ Health (Abingdon) 2003, 16:230.

2. Parkin DM, Bray F, Ferlay J, Pisani P: Global cancer statistics, 2002. CA Cancer J Clin 2005, 55:74-108.

3. Bahl A, Falk S: Meta-analysis of single agents in the chemotherapy of NSCLC: what do we want to know? Br J Cancer 2001, 84:1143-1145.

4. Viktorsson $K$, De Petris $L$, Lewensohn R: The role of p53 in treatment responses of lung cancer. Biochem Biophys Res Commun 2005, 331:868-880

5. Motadi LR, Misso NL, Dlamini Z, Bhoola KD: Molecular genetics and mechanisms of apoptosis in carcinomas of the lung and pleura: therapeutic targets. Int Immunopharmacol 2007, 7:1934-1947.

6. Sato M, Shames DS, Gazdar AF, Minna JD: A translational view of the molecular pathogenesis of lung cancer. J Thorac Oncol 2007, 2:327-343.

7. Bosken $\mathrm{CH}$, Wei $\mathrm{Q}, \mathrm{Amos} \mathrm{Cl}$, Spitz MR: An analysis of DNA repair as a determinant of survival in patients with non-small-cell lung cancer. $J$ Natl Cancer Inst 2002, 94:1091-1099.

8. Bernig T, Chanock SJ: Challenges of SNP genotyping and genetic variation: its future role in diagnosis and treatment of cancer. Expert Rev Mol Diagn 2006, 6:319-331.

9. Thompson LH, Brookman KW, Jones NJ, Allen SA, Carrano AV: Molecular cloning of the human XRCC1 gene, which corrects defective DNA strand break repair and sister chromatid exchange. Mol Cell Biol 1990, 10:6160-6171.

10. Thompson LH, West MG: XRCC1 keeps DNA from getting stranded. Mutat Res 2000, 459:1-18.

11. Dianov GL, Prasad R, Wilson SH, Bohr VA: Role of DNA polymerase beta in the excision step of long patch mammalian base excision repair. J Biol Chem 1999, 274:13741-13743.

12. Caldecott KW, McKeown CK, Tucker JD, Ljungquist S, Thompson LH: An interaction between the mammalian DNA repair protein XRCC1 and DNA ligase III. Mol Cell Biol 1994, 14:68-76.

13. Vidal AE, Boiteux S, Hickson ID, Radicella JP: XRCC1 coordinates the initial and late stages of DNA abasic site repair through protein-protein interactions. EMBO J 2001, 20:6530-6539.

14. Abdel-Rahman SZ, El-Zein RA: The $399 \mathrm{Gln}$ polymorphism in the DNA repair gene XRCC1 modulates the genotoxic response induced in human lymphocytes by the tobacco-specific nitrosamine NNK. Cancer Lett 2000, 159:63-71

15. Matullo G, Palli D, Peluso M, Guarrera S, Carturan S, Celentano E, Krogh V, Munnia A, Tumino R, Polidoro S, Piazza A, Vineis P: XRCC1, XRCC3, XPD gene polymorphisms, smoking and (32)P-DNA adducts in a sample of healthy subjects. Carcinogenesis 2001, 22:1437-1445.

16. Savas S, Kim DY, Ahmad MF, Shariff M, Ozcelik H: Identifying functional genetic variants in DNA repair pathway using protein conservation analysis. Cancer Epidemiol Biomarkers Prev 2004, 13:801-807.

17. Lamerdin JE, Montgomery MA, Stilwagen SA, Scheidecker LK, Tebbs RS, Brookman KW, Thompson LH, Carrano AV: Genomic sequence comparison of the human and mouse XRCC1 DNA repair gene regions. Genomics 1995, 25:547-554.

18. Sun X, Li F, Sun N, Shukui Q, Baoan C, Jifeng F, Lu C, Zuhong L, Hongyan C, YuanDong C, Jiazhong J, Yingfeng Z: Polymorphisms in XRCC1 and XPG and response to platinum-based chemotherapy in advanced non-small cell lung cancer patients. Lung Cancer 2009, 65:230-236.

19. Song D-G, Liu J, Wang Z-H, Song B, Li C-z: Single nucleotide polymorphisms in XRCC1 and clinical response to platin-based chemotherapy in advanced non-small cell lung cancer. Zhong Liu Fang Zhi Yan Jiu 2007, 34:845-847, (Chinese).

20. Wang Z-H, Miao X-P, Tan W, Zhang X-R, Xu B-H, Lin D-X: Single nucleotide polymorphisms in XRCC1 and clinical response to platin-based chemotherapy in advanced non small cell lung cancer. Chin J Cancer 2004, 23:865-868, (Chinese).

21. Hong $C-Y, X u$ Q, Yue Z, Zhang $Y$, Yuan $Y$ : Correlation of the sensitivity of NP chemotherapy in non-small lung cancer with DNA repair gene XRCC1 polymorphism. Chin J Cancer 2009, 28:1291-1297, (Chinese).

22. Jin Y-W, Liu J, Wang Z-H: Prediction of XPD and XRCC1 gene polymorphisms in advanced non-small cell lung cancer patients receiving platinum-based chemotherapy. Shandong Yi Yao 2006, 46:42-43, (Chinese).
23. Qian X-P, Qiu L-X, Yang Y, Min Jiang, Zhang Y, Yu L-X, Wang L-F, Hu W-J, Liu B-R: Predictive value of base-excision repair gene polymorphisms in advanced non-small cell lung cancer patients receiving platinum-based chemotherapy. Mod Oncol 2010, 18:1303-1304, (Chinese).

24. Gao C-M, Shi M-Q, Wu J-Z, Cao H-X, Feng J-F, Xu L: Polymorphisms in XRCC1 gene and sensitivity to gemcitabine/cisplat in chemotherapy in non small cell lung cancer. Practical J Cancer 2006, 21:351-353, (Chinese).

25. Ding C, Liu L, Song H: Polymorphism in XRCC1 and sensitivity to platinbased chemotherapy in advanced non-small cell lung cancer. China Pharm 2010, 13:1399-1401, (Chinese).

26. Yuan $P$, Miao X-P, Zhang X-M, Wang Z-H, Tan W, Sun $Y$, Zhang X-R, Xu B-H, Lin D-X: XRCC1 and XPD genetic polymorphisms predict clinical responses to platinum-based chemotherapy in advanced non-small cell lung cancer. China J Oncol 2006, 28:196-198, Chinese.

27. Shi M-Q, Gao C-M, Wu J-H, Cao H-H, Feng J-F, Xu L, Lu J-W, Wang L: Polymorphisms in XRCC1 gene and sensitivity to platin2based chemotherapy in advanced lung cancer. Chin Clin Oncol 2006, 11:575-578584, (Chinese).

28. Qiu L-X, Qian X-P, Liu B-R, Hu W-J, Yang Y, Yu L-XIA, Liu X-Z, Yan W-Y: Predictive value of XRCC1 polymorphisms in advanced non-small cell lung cancer patients receiving platinum-based chemotherapy. Mod Oncol 2009, 17:263-265 (Chinese).

29. Cheng H-Y, Chen B-A, Sun X-C, Sun N, Deng Y-X, Cao Y-D: Relationship of single nucleotide polymorphisms and clinical response to platinumbased chemotherapy in advanced non-small cell lung cancer. Jiang Su Med J 2011, 37:272-274 (Chinese)

30. Giachino DF, Ghio P, Regazzoni S, Mandrile G, Novello S, Selvaggi G, Gregori D, DeMarchi M, Scagliotti GV: Prospective assessment of XPD Lys751GIn and XRCC1 Arg399GIn single nucleotide polymorphisms in lung cancer. Clin Cancer Res 2007, 13:2876-2881.

31. Butkiewicz D, Rusin M, Sikora B, Lach A, Chorąży M: An association between DNA repair gene polymorphisms and survival in patients with resected non-small cell lung cancer. Mol Biol Rep 2011, 38:5231-5241.

32. de las Peñas R, Sanchez-Ronco M, Alberola V, Taron M, Camps C, GarciaCarbonero R, Massuti B, Queralt C, Botia M, Garcia-Gomez R, Isla D, Cobo M, Santarpia M, Cecere F, Mendez P, Sanchez JJ, Rosell R, Spanish Lung Cancer Group: Polymorphisms in DNA repair genes modulate survival in cisplatin/gemcitabine-treated non-small-cell lung cancer patients. Ann Oncol 2006, 17:668-675.

33. Yin Z, Zhou B, He Q, Li M, Guan P, Li X, Cui Z, Xue X, Su M, Ma R, Bai W, Xia S, Jiang $Y, X u S, L V Y$, Li X: Association between polymorphisms in DNA repair genes and survival of non-smoking female patients with lung adenocarcinoma. BMC Cancer 2009, 9:439.

34. Sreeja L, Syamala VS, Syamala V, Hariharan S, Raveendran PB, Vijayalekshmi RV, Madhavan J, Ankathil R: Prognostic importance of DNA repair gene polymorphisms of XRCC1 Arg399GIn and XPD Lys751GIn in lung cancer patients from India. J Cancer Res Clin Oncol 2008, 134:645-652.

35. Gurubhagavatula S, Liu G, Park S, Zhou W, Su L, Wain JC, Lynch TJ, Neuberg DS, Christiani DC: XPD and XRCC1 genetic polymorphisms are prognostic factors in advanced non-small-cell lung cancer patients treated with platinum chemotherapy. J Clin Oncol 2004, 22:2595-2601.

36. Kalikaki A, Kanaki M, Vassalou H, Souglakos J, Voutsina A, Georgoulias V, Mavroudis D: DNA repair gene polymorphisms predict favorable clinical outcome in advanced non-small-cell lung cancer. Clin Lung Cancer 2009, 10:118-123.

37. Liu X-Z, Qian X-P, Liu B-R, Hu W-J, Wang L-F, Wei J, Yu L-X: Single nucleotide polymorphism in XRCC2, XPD and platinum prognosis in non-small cell lung cancer patients. J Clin Med Pract 2008, 12:7-12, (Chinese).

38. Han JY, Yoon KA, Park JH, Lee YJ, Lee GK, Han JH, Yoon SJ, Yun T, Kim HT Lee JS: DNA repair gene polymorphisms and benefit from gefitinib in never-smokers with lung adenocarcinoma. Cancer 2011, 117:3201-3208.

39. Yao CY, Huang XE, Li C, Shen HB, Shi MQ, Feng JF, Pan LX, Tang JH: Lack of influence of XRCC1 and XPD gene polymorphisms on outcome of platinum-based chemotherapy for advanced non small cell lung cancers. Asian Pac J Cancer Prev 2009, 10:859-864.

40. Hung RJ, Hall J, Brennan P, Boffetta P: Genetic polymorphisms in the base excision repair pathway and cancer risk: a HuGE review. Am J Epidemiol 2005, 162:925-942 
41. Zienolddiny S, Campa D, Lind H, Ryberg D, Skaug V, Stangeland L, Phillips DH, Canzian F, Haugen A: Polymorphisms of DNA repair genes and risk of non-small cell lung cancer. Carcinogenesis 2006, 27:560-567.

42. Shen M, Berndt SI, Rothman N, Mumford JL, He X, Yeager M, Welch R Chanock S, Keohavong P, Donahue M, Zheng T, Caporaso N, Lan Q: Polymorphisms in the DNA base excision repair genes APEX1 and XRCC1 and lung cancer risk in Xuan Wei, China. Anticancer Res 2005, 25:537-542.

43. De Ruyck K, Szaumkessel M, De Rudder I, Dehoorne A, Vral A, Claes K, Velghe A, Van Meerbeeck J, Thierens H: Polymorphisms in base-excision repair and nucleotide-excision repair genes in relation to lung cancer risk. Mutat Res 2007, 631:101-110.

44. Zhou W, Liu G, Miller DP, Thurston SW, Xu LL, Wain JC, Lynch TJ, Su L, Christiani DC: Polymorphisms in the DNA repair genes XRCC1 and ERCC2, smoking, and lung cancer risk. Cancer Epidemiol Biomarkers Prev 2003, 12:359-365.

45. Park JY, Lee SY, Jeon HS, Bae NC, Chae SC, Joo S, Kim CH, Park JH, Kam S, Kim IS, Jung TH: Polymorphism of the DNA repair gene XRCC1 and risk of primary lung cancer. Cancer Epidemiol Biomarkers Prev 2002, 11:23-27.

46. Li M, Yin Z, Guan P, Li X, Cui Z, Zhang J, Bai W, He Q, Zhou B: XRCC1 polymorphisms, cooking oil fume and lung cancer in Chinese women nonsmokers. Lung Cancer 2008, 62:145-151.

47. Wu X, Gu J, Wu TT, Swisher SG, Liao Z, Correa AM, Liu J, Etzel CJ, Amos Cl, Huang M, Chiang SS, Milas L, Hittelman WN, Ajani JA: Genetic variations in radiation and chemotherapy drug action pathways predict clinical outcomes in esophageal cancer. J Clin Oncol 2006, 24:3789-3798.

48. Siddiqi N: Publication bias in epidemiological studies. Cent Eur J Public Health 2011, 19:118-120.

\section{Pre-publication history}

The pre-publication history for this paper can be accessed here: http://www.biomedcentral.com/1471-2407/12/71/prepub

doi:10.1186/1471-2407-12-71

Cite this article as: Cui et al: Association between polymorphisms in XRCC1 gene and clinical outcomes of patients with lung cancer: a meta-analysis. BMC Cancer 2012 12:71.

\section{Submit your next manuscript to BioMed Central} and take full advantage of:

- Convenient online submission

- Thorough peer review

- No space constraints or color figure charges

- Immediate publication on acceptance

- Inclusion in PubMed, CAS, Scopus and Google Scholar

- Research which is freely available for redistribution

Submit your manuscript at www.biomedcentral.com/submit
Biomed Central 